\title{
REFLEXIONES A PROPOSITO \\ DE LA REALIDAD SOCIAL, \\ LA TRADICIÓN JURÍDICA Y \\ LA MORAL CRISTIANA EN EL \\ MATRIMONIO ROMANO ( I )
}

\section{Antonio Fernández de Buján}

Professor catedrático de Direito Romano da Universidade

Autônoma de Madrid (Espanha)

antonio.bujan@uam.es

Sumário: Introducción. 1) Terminología y definiciones de matrimonio. 2) Matrimonio libre. Matrimonio cum manu. 3) Uniones de hecho. Contubernio. 4) Esponsales. 5) Naturaleza jurídica.

Resúmen: El matrimonio como toda institución que tiene una tradición de siglos es un producto histórico. Constituye la expresión en cada época de una moral y de unos usos sociales, en la que se reflejan, si bien en una mayor medida en unas etapas que en otras, las tensiones, equilibrios, resistencias y oscilaciones, que las nuevas realidades o los cambios de mentalidad en una parte del universo social, producen en la valoración intrínseca de la institución, así como en el juego de fuerzas contrarias que aspiran a su conservación o remodelación. Sólo desde la interpretación de las fuentes de conocimiento que conforman la experiencia histórica que supuso la clásica, y siempre latente, tensión entre una concepción laica y secularizadora del matrimonio y otra concepción propia de una moral sacralizada y canónica, podrá procederse con fundamento a una adecuada valoración de la realidad presente, de su regulación jurídica y, en su caso, a su eventual reforma. El modelo matrimonial que caracteriza, en buena medida, en sus diferentes perspectivas, la denominada tradición de pensamiento occidental europeo y americano, tiene sus principales fuentes en el Derecho romano y en el Derecho canónico . Pero sentada esta afirmación, que parece tener un carácter indubitable, no se ponen de acuerdo los autores sobre el papel y el grado de influencia ejercido por cada una de éstas. Se llegado incluso a afirmar por algunos autores que la institución del matrimonio romano constituye la más grande de las creaciones de su genio jurídico, frente a otros estudiosos que, ubicados en el polo opuesto, opinan que es el matrimonio la institución en la que más se ha echado en falta el genio jurídico de Roma.

Palabras clabe: Matrimónio. Derecho Romano. Naturaleza jurídica. 


\section{INTRODUCCIÓN}

El matrimonio como toda institución que tiene una tradición de siglos es un producto histórico. Constituye la expresión en cada época de una moral y de unos usos sociales, en la que se reflejan, si bien en una mayor medida en unas etapas que en otras, las tensiones, equilibrios, resistencias y oscilaciones, que las nuevas realidades o los cambios de mentalidad en una parte del universo social, producen en la valoración intrínseca de la institución, así como en el juego de fuerzas contrarias que aspiran a su conservación o remodelación. Sólo desde la interpretación de las fuentes de conocimiento que conforman la experiencia histórica que supuso la clásica, y siempre latente, tensión entre una concepción laica y secularizadora del matrimonio y otra concepción propia de una moral sacralizada y canónica, podrá procederse con fundamento a una adecuada valoración de la realidad presente, de su regulación jurídica y, en su caso, a su eventual reforma ${ }^{6}$.

El modelo matrimonial que caracteriza, en buena medida, en sus diferentes perspectivas, la denominada tradición de pensamiento occidental europeo, tiene sus principales fuentes en el Derecho romano y en el Derecho canónico ${ }^{7}$. Pero sentada

\footnotetext{
${ }^{06}$ Vid en este sentido en GAUDEMET, El matrimonio en Occidente, Madrid 1993, pp.15 ss.

${ }^{07}$ Sobre bibliografía de matrimonio, véase entre otra: ALBERTARIO, La definizione del matrimonio secondo Modestino, Studi Albertoni,Padova 1933; Voltearla nozione giuridica del conubium ,Studi in memoria Albertario,II,Milano 1953,pp.345ss Id.,La conception du mariage à Rome,RIDA.1955 ROBLEDA OLIS, S., Sobre el matrimonio en derecho romano, en SDHI 37 (1971) 337-350; TOMULESCU, C., Les rapports entre le mariage et la manus, en RIDA 18 (1971) 723-733; VOLTERRA, E., Precisazioni in tema di matrimonio classico, en BIDR 78 (1975) 245-270; LONGO, G., Ancora sul matrimonio romano, en SDHI 43 (1977) 459-480;
}

ANKUM, H., Le mariage et les conventions matrimoniales des mineurs. etudes sur le statut juridique des enfants mineurs dans l' histoire du droit privé neerlandais a partir du treizieme siecle, IV a, 1, en TR 46 (1978) 203-249; DAUBE, D., Historical aspects of informal marriage, en RIDA 25 (1978) 95-107;

GAUDEMET, J., L' interpretation du principe d' indissolubilité du mariage Chretien au cors du premier millenaire, en BIDR 81 (1978) 11-70;MAC CORMACK, G., Coemptio and marriage by purchase, en BIDR 81 (1978) 179-199; VAN DE WIEL, C., La legitimation par mariage subsequent,de costantin ájustinien. sa reception sporadique dans le droit byzantin, en RIDA 25 (1978) 307-350;

VAN HUMBEECK, J., Exploitation et repression des jeux d' argent en flandre aux 14 et 15 siecles, en TR 46 (1978) 327-352; VAN DE WIEL, W., Complements a la legitimation par mariage subsequent sous justinien et dans le droit greco-romain, en RIDA 26 (1979) 453-473; RODA, S., Il matrimonio fra cugini germani nella legislazione tardoimperiale, en SDHI 45 (1979) 289-309; THOMAS, Y Mariages endogamiques á Rome. patrimoine, pouvoir et parenté depuis l' epoque archaieque, en RHDFE 58 (1980) 345-382; FALCHI, G., Osservazioni sulla natura della "coemptio matrimonii causa" nel diritto preclassico, en SDHI 50 (1984) 355-382; JIMÉNEZ GARNICA, A., El origen de la legislación civil visigoda sobre la prohibición de matrimonios entre romanos y godos: un problema de fundamento religioso, en AHDE 55 (1985) 735-747; CASTELLO, C., Remarques sur des cas concernant le debut du iustum matrimonium, en RIDA 32 (1985) 237-246; SARGENTI, M., Matrimonio cristiano e societá pagana. (Spunti per una ricerca), en SDHI 51 (1985) 367-391; ZABLOCKA, M., Le modifiche introdotte nelle leggi matrimoniali augustee sotto la dinastia giulio-claudia, en BIDR 89 (1986) 379-410. DESANTI, L., Costantino e il matrimonio fra 
esta afirmación, que parece tener un carácter indubitable, no se ponen de acuerdo los autores sobre el papel y el grado de influencia ejercido por cada una de éstas. Se llegado incluso a afirmar por algunos autores que la institución del matrimonio romano constituye la más grande de las creaciones de su genio jurídico, frente a otros estudiosos que, ubicados en el polo opuesto, opinan que es el matrimonio la institución en la que más se ha echado en falta el genio jurídico de Roma, por lo que no cabría hablar de un derecho clásico romano en esta materia, sino que lo clásico, en lo que afecta al régimen jurídico del matrimonio, sería el Derecho canónico ${ }^{8}$.

\section{TerminologíA Y DEFINICIONES DE MATRIMONIO}

En las fuentes romanas de las diferentes épocas se utilizan muy diversos vocablos para designar o para referirse a la realidad social y jurídica que constituye el matrimonio: matrimonium, nuptiae, consortium, coniunctio, communicatio, societas, pactum, foedus, etc. Sobre la relación de las voces romanas con la terminología moderna al respecto, ha escrito recientemente ORTEGA CARRILLO DE ALBORNOZ que tradicionalmente para designar la unión solemne de un hombre y una mujer, si bien utilizamos promiscuamente los términos matrimonio, nupcias, bodas, casamiento e incluso esponsales, es preciso delimitar el ámbito de aplicación de dichos términos que difieren en sus orígenes etimológicos y en su primigenio significado 9 . En uno de los textos con los que principia el Digesto, D.1.1.3, Ulpiano afirma que la unión, coniunctio, que en las personas llamamos matrimonio, es de derecho natural, porque es enseñada por la naturaleza a todo ser

tutore e pupilla, en BIDR 89 (1986) 443-463; DESANTI, L., Costantino, il ratto e il matrimonio riparatore, en SDHI 52 (1986) 195-217; DESANTI, L., Sul matrimonio di donne consacrate a Dio nel diritto romano cristiano, en SDHI 53 (1987) 270-296; DE BONFILS, G., Legislazione ed ebrei nel 4 secolo. il divieto dei matrimoni misti, en BIDR 90 (1987) 389-438; LOOPER-FRIEDMAN, S., The decline of manus-marriage in Rome, en TR 55 (1987) 281-296; GAUDEMET, J. Union libre et mariage dans la Rome imperiale, en IVRA 40 (1989) 1-23; HANARD, G., Manus et mariage a l'epoque archaique. Un essai de mise en perspective ethnologique, en RIDA 36 (1989) 161-279; PIRO, I., "Conventio in manum" e successivo matrimonio in Gai 2. 139, en Labeo 35 (1989) 307-335; LUCHETTI, G., Il matrimonio "cum scriptis" e "sine scriptis" nelle fonti giuridiche Giustinianee, en BIDR 92-93, (1989-1990) 325-376; SANCHO, L., El matrimonio romano primitivo y el valor de la lex inhumanissima (Cic. rep. 2,37,62), en RIDA 37 (1990) 347-383; PETER, O., "liberorum quaerundorum causa". L' image ideale du mariage et de la filiation a Rome, en RIDA 38 (1991) 285-331; MIQUEL, Consortium omnis vitae. Anales Facultad de Derecho Univ. La Laguna, 20, 2203 MARTÍN MINGUIJON, Modelos de familia en España. Antecedentes históricos, en Revista General de Derecho Romano Iustel.com no 5, 2005 www.iustel.com.

${ }^{08}$ Vid. por todos, en relación con el matrimonio canónico, NAVARRO VALLS, Matrimonio y Derecho, 1995 y la bibliografía allí citada.

${ }^{09}$ ORTEGA CARRILLO DE ALBORNOZ, Precisiones terminológicas: Nuptias y Matrimonium, Revista General de Derecho Romano, Iustel.com n ${ }^{\circ}$ 5, 2005. www.iustel.com 
vivo sobre la tierra, en el mar o en el aire ${ }^{10}$. La probable alusión ulpianea al deseo sexual como elemento común a hombres y animales, por mor de la naturaleza, había sido ya destacada por diversos autores, con anterioridad, entre ellos Cicerón, en De officiis I.40.11 ${ }^{11}$. Son varios los textos, sin embargo, en los que se señala que es la unión de las voluntades de los cónyuges, y no la unión de los cuerpos, lo que caracteriza el matrimonio. Así se manifiesta el propio Ulpiano en D. 24.1.32.13: «No es la unión sexual lo que hace el matrimonio, sino la affectio matrimonial» ${ }^{12}$. En este mismo sentido en D.50.17.30 y D. 24.1.32.13 ${ }^{13}$.

En las fuentes romanas se conservan dos definiciones de matrimonio. Ambas son aplicables, en su esencia, a la época clásica, dado que el matrimonio, y la familia en general, es una de las instituciones que ha experimentado una mayor evolución a lo largo de las varias épocas de historia del Derecho romano. Una de estas dos definiciones, la contenida en el Digesto y atribuida a Modestino, es quizás la que ha obtenido un mayor eco de todas las formuladas sobre la institución. A su difusión ha contribuido, sin duda, su aceptación, con una somera adaptación, por el Derecho canónico medieval y su inclusión en el Decreto de Graciano. La otra de las definiciones sobre matrimonio se contiene en las Instituciones de Justiniano. En ambas definiciones se pone el acento sobre el proyecto de vida en común de dos personas, como elemento esencial que configura la institución. En este sentido, se ha resaltado el carácter sociológico del texto del jurista, así como la ausencia en el mismo de la dimensión familiar y de los principales efectos jurídicos dimanantes de la unión conyugal.

Para Modestino el matrimonio, nuptiae, es una unión, coniunctio maris et feminae, de un hombre y una mujer, una comunidad para toda la vida, consortium omnis vitae, y una puesta en común del derecho divino y del derecho humano, divini et humanis iuris communicatio ${ }^{14}$. La referencia al consorcio para toda la vida

${ }^{10}$ D.1.1.3: Ulpianus 1 inst. "Ius naturale est, quod natura omnia animalia docuit: nam ius istud non humani generis proprium, sed omnium animalium, quae in terra, quae in mari nascuntur, avium quoque commune est. hinc descendit maris atque feminae coniunctio, quam nos matrimonium appellamus, hinc liberorum procreatio, hinc educatio: videmus etenim cetera quoque animalia, feras etiam istius iuris peritia censeri".

${ }^{11}$ Commune autem animantium omnium est coniunctionis procreandi causa

12 D. 24.1.32.13: Ulpianus 33 ad sab.

Si mulier et maritus diu seorsum quidem habitaverint, sed honorem invicem matrimonii habebant ( quod scimus interdum et inter consulares personas subsecutum), puto donationes non valere, quasi duraverint nuptiae: non enim coitus matrimonium facit, sed maritalis affectio: si tamen donator prior decesserit, tunc donatio valebit

${ }^{13}$ D.50.17.30: Ulpianus 36 ad sab. "Nuptias non concubitus, sed consensus facit” y D. 24.1.32.13: Ulpianus 33 ad sab. "Si mulier et maritus diu seorsum quidem habitaverint, sed honorem invicem matrimonii habebant ( quod scimus interdum et inter consulares personas subsecutum), puto donationes non valere, quasi duraverint nuptiae: non enim coitus matrimonium facit, sed maritalis affectio: si tamen donator prior decesserit, tunc donatio valebit".

${ }^{14}$ D.23.2.1: Modestinus 1 reg. Nuptiae sunt coniunctio maris et feminae et consortium omnis vitae, divini et humani iuris communicatio. 
debe ser interpretada en el sentido de que no se concebía que los esposos acordasen permanecer unidos un periodo de tiempo determinado, pero no a la indisolubilidad de la unión, dado que la posibilidad de disolver el matrimonio, en el supuesto que no se mantuviese por los esposos la intención de permanecer juntos, affectio maritalis, era para el Derecho romano de todas las épocas, en especial en la etapa clásica, una solución inherente a la propia naturaleza de la institución.

La mención, en la definición de Modestino, a la puesta en común del derecho divino y humano, a la que ya había hecho alusión Cicerón en De amicitia ${ }^{15}$, haría referencia al conjunto de normas jurídicas y preceptos religiosos aplicables de consuno a los dos miembros de la unión conyugal ${ }^{16}$.

En las Instituciones de Justiniano, las nupcias o matrimonio, se configuran como la unión de un hombre y una mujer, nuptiae autem sive matrimonium est viri et mulieris coniunctio, que comporta una vida en común, individuam consuetudinem vitae continens ${ }^{17}$. En otro texto de las Instituciones se reitera la idea de la vida en común como el fundamento de la noción de matrimonio, maris et feminae coniugatio, quam nos matrimonium appellamus ${ }^{18}$.

La naturaleza comunitaria o societaria del matrimonio romano es asimismo resaltada, conforme ha puesto de relieve por LOBRANO,NOTA: PONER LA NOTA DE FINAL DEL PARRAFO. en diversos textos jurídicos y literarios. Así en una Constitución del año 242, atribuida a Gordiano, NOTA CJ.9.32.4.pr.. se afirma la condición de socia de la mujer casada, socia rei humanae et divinae domus: «los sucesores del marido fallecido no pueden ejercitar la acción de herencia arrebatada contra la mujer, que es en la casa común, socia de las cosas divinas y humanas».NOTA,LOBRANO, Uxor quodammodo domina, reflessioni su Paul.D.25.2.1,Sassari 1989.

En el mismo sentido, en un texto contenido en el Digesto, Paulo subraya que «la acción por las cosas arrebatadas se introdujo contra la mujer divorciada, pero no se admitió que se pueda dar contra ella la acción de hurto, por su carácter infamante para el honor de la matrona, y porque la comunidad de vida con su marido la hace en cierta medida propietaria de esas cosas».NOTA D.25.2.1. Vid asimismo en Guarino,Res amotae, Atti dell'Accademia di Scienze marali e politiche 75, Nápoli 1965 ,pp 257 ss.

${ }^{16} \mathrm{Vid}$ al respecto en, LANFRANCHI, La definizione del marimonio nei retori romani, Atti del colloquio romanístico-cánonico, Roma 1979, pp 267-298.

${ }^{17}$ I.1.2.pr.: hinc descendit maris atque feminae coniugatio, quam nos matrimonium appellamus, hinc liberorum procreatio et educatio

${ }^{18}$ I.1.9.1: Nuptiae autem sive matrimonium est viri et mulieris coniunctio, individuam consuetudinem vitae continens. 
Asimismo en un texto de Trifonino, en relacion con el ejercicio de la acción de las cosas amovidas, se deja entrever el reciproco status de los cónyuges a propósito de lo que el jurista denomina societatis vitae (nota d.42.1.52).

La condición de socia de la esposa en la sociedad conyugal es puesta de relieve, entre otros textos literarios, recogidos en el estudio de Lobrano.Asipor Ej en la obra de Salustio, que contrapone la ventaja que supone la monogamia que caracteriza al matrimonio romano y la consideración, en el seno del mismo, de socia de la esposa, frente a la poligamia de otros pueblos. Asimismo Varrón y Cicerón entienden que el matrimonio, por su propia naturaleza, es una sociedad y los cónyuges son los socios. Ovidio acuña la que quizás quepa considerar más brillante de las caracterizaciones del matrimonio, al definirlo como una sociedad de afectos y de bienes, en la que los cónyuges son dueños de la fortuna familiar.

A la especial caracterización, en sentido generico, de la sociedad en Roma, se refiere Bianchini cuando afirma que: <en epoca originaria, y probablemente a la largo de toda la época clásica, con el término societas se haría referencia no a un acto jurídico bilateral o plurilateral, sino simplemente a una relación asociativa, duradera, de colaboración o coordinación entre diversas personas, con independencia de la fuente que le da origen> NOTA:Bianchini, Studi sulla societas, Milano 1967, pp.18ss.

\section{Matrimonio libre. Matrimonio cum Manu.}

En los primeros siglos de existencia de la comunidad política romana, la mera situación de convivencia de hecho, con carácter estable, entre dos personas de distinto sexo, con intención de constituir un matrimonio, no produce, sin embargo, por sí misma, efectos jurídicos de especial relevancia, a no ser que esa relación matrimonial se configure en el marco de la familia agnaticia. En sentido estricto, con la expresión familia agnaticia o familia propio iure $\operatorname{dicta}^{19}$, se hace referencia al grupo de personas sometidas a la autoridad del mismo paterfamilias, iure propio familiam dicimus plures personas, quae sunt sub unius potestate, o

${ }^{19}$ D.50.16.195.2: Ulpianus 46 ad ed. "Familiae appellatio refertur et ad corporis cuiusdam significationem, quod aut iure proprio ipsorum aut communi universae cognationis continetur. iure proprio familiam dicimus plures personas, quae sunt sub unius potestate aut natura aut iure subiectae, ut puta patrem familias, matrem familias, filium familias, filiam familias quique deinceps vicem eorum sequuntur, ut puta nepotes et neptes et deinceps. pater autem familias appellatur, qui in domo dominium habet, recteque hoc nomine appellatur, quamvis filium non habeat: non enim solam personam eius, sed et ius demonstramus: denique et pupillum patrem familias appellamus. et cum pater familias moritur, quotquot capita ei subiecta fuerint, singulas familias incipiunt habere: singuli enim patrum familiarum nomen subeunt. idemque eveniet et in eo qui emancipatus est: nam et hic sui iuris effectus propriam familiam habet. communi iure familiam dicimus omnium adgnatorum: nam etsi patre familias mortuo singuli singulas familias habent, tamen omnes, qui sub unius potestate fuerunt, recte eiusdem familiae appellabuntur, qui ex eadem domo et gente proditi sunt". 
bien por naturaleza, aut naturae, es decir, por vínculos de consaguinidad, como los hijos varones o mujeres, nacidos de justas nupcias, o bien en virtud de una relación jurídica, aut iure, como su esposa, si ésta ha contraído uno de los tipos de matrimonio, enmarcados dentro de la institución denominada conventio in manum, que tiene como corolario la integración de la mujer en la familia de su marido, como hija, loco filia, si el marido era sui iuris, o como nieta, loco nepta, si el marido era alieni iuris $y$, por tanto, estaba sometido a potestad ajena, o bien las esposas de sus hijos sometidos a patria potestad, o bien personas que hayan quedado sometidas a su potestad como consecuencia de la realización de una adrogatio o de una adoptio. En expresión de BURDESE, la familia en época arcaica se configura como una comunidad unitaria y solidaria, en relación con las creencias religiosas, las exigencias económicas y la mentalidad de su tiempo ${ }^{20}$.

Cabía asimismo la posibilidad de que la mujer, al contraer matrimonio, decidiese, o se le permitiese, aunque ello no constituía la situación más frecuente, no integrarse en la familia de su marido, con lo que el matrimonio libre o contraído sine manu, implicaba un régimen de separación de bienes entre los cónyuges. En este supuesto, si la mujer era sui iuris, es decir, no estaba sometida a potestad ajena, en época republicana, quedaba sometida a la potestad de un tutor, que debía prestar su autorización, o de forma supletoria cabría recurrir a la autorización del magistrado, para realizar determinados actos. El evidente anacronismo de la tutela de las mujeres, visualizado ya en la república avanzada, desemboca en la supresión de la institución en la época clásica ${ }^{21}$.

En los supuestos de matrimonios cum manu, que constituían la mayoría en las etapas arcaica y republicana, la posición de subordinación de la mujer a la potestad de su marido o a la del paterfamilias al que, en su caso, estuviese sometido su marido, era semejante a la que se encontraba cualquier otra persona sometida a potestad ajena ${ }^{22}$. Las fórmulas jurídicas a través de las cuales se podría la incorporación de la mujer a la familia de su marido eran: a) la confarreatio, que quizás era accesible tan sólo a los contrayentes patricios, podría considerarse un tipo de matrimonio religioso, en atención a la intervención del Pontífice Máximo, de sacerdotes de Júpiter, y a la necesidad de cumplimiento de determinados ritos religiosos ${ }^{23}$; b) la coemptio, que requería la entrega por parte del futuro marido

${ }^{20}$ BURDESE, Diritto Privato Romano, Torino 1987, p.226.

${ }^{21}$ Sobre la tutela de las mujeres y la posición de la mujer en el matrimonio libre vid. En GARCÍA GARRIDO, Ius uxorium, El régimen matrimonial de la mujer casada en derecho romano. Madrid 1958.

${ }^{22}$ GAYO, I.1.110: Olim itaque tribus modis in manum conveniebant: usu, farreo, coemptione.

${ }^{23}$ GAYO I.112: Farreo in manum conveniunt per quoddam genus sacrificii, quod Iovi Farreo fit; in quo farreus panis adhibetur, unde etiam confarreatio dicitur; complura praeterea huius iuris ordinandi gratia cum certis et sollemnibus verbis praesentibus decem testibus aguntur et fiunt. Quod ius etiam nostris temporibus in usu est: Nam flamines maiores, id est Diales, Martiales, Quirinales, item reges sacrorum, nisi ex farreatis nati non leguntur: Ac ne ipsi quidem sine confarreatione sacerdotium habere possunt. 
de una compensación económica al paterfamilias o al tutor al que estuviese sometida la mujer, como acto previo y compensatorio a la disgregación de ésta de su familia de origen y posterior integración en la familia de su futuro marido ${ }^{24}$; y c) El usus, que exigía la convivencia continuada de los futuros cónyuges durante un año, transcurrido el cual se producía la incardinación de la mujer en la familia de su marido. Si faltaba la voluntad de incorporación a la nueva familia, bastaba con que la mujer se ausentase, con esta intención, durante tres días seguidos del domicilio conyugal ${ }^{25}$.

La concepción agnaticia de la familia, en la que se integraba el matrimonio cum manu, y que se fundamentaba en la subordinación de los miembros de la unidad familiar a la potestad del paterfamilias, comenzó a cuestionarse en los últimos siglos de la república ${ }^{26}$. La evolución de la mentalidad de la propia sociedad romana, cristalizada en singulares leyes públicas y en el ejercicio de la potestad jurisdiccional de los pretores, se manifiesta en:

a) El cuestionamiento de la conformación artificiosa de la familia agnaticia y de sus, en ocasiones, perniciosos efectos jurídicos, que de forma paulatina es relegada, en el tratamiento legislativo, en beneficio de la concepción de la familia basada en lazos de consanguinidad.

b) La atenuación del carácter absoluto de la potestad del paterfamilias, concretada no sólo en la limitación de sus facultades, sino también en la imposición de nuevas obligaciones y, en general, en la progresiva conformación de su preeminente posición jurídica como tuitiva de las personas que forman parte de su familia.

c) La disminución de matrimonios cum manu, en los que la mujer, como ya se ha señalado, se incorporaba a la familia de su marido y se sometía a la patria potestad de éste o del paterfamilias al que estuviese, en su caso, sometido su marido y, en consecuencia, el constante aumento de los matrimonios libres, que llega a ser la forma más usual de relación matrimonial a fines de la república,

${ }^{24}$ GAYO I.113 y 114: 113. Coemptione vero in manum conveniunt per mancipationem, id est per quandam imaginariam venditionem: Nam adhibitis non minus quam V testibus civibus Romanis puberibus, item libripende, emit vir mulierem, cuius in manum convenit. 114. Potest autem coemptionem facere mulier non solum cum marito suo, sed etiam cum extraneo; scilicet aut matrimonii causa facta coemptio dicitur aut fiduciae; quae enim cum marito suo facit coemptionem, ut apud eum filiae loco sit, dicitur matrimonii causa fecisse coemptionem; quae uero alterius rei causa facit coemptionem aut cum viro suo aut cum extraneo, velut tutelae evitandae causa, dicitur fiduciae causa fecisse coemptionem.

${ }^{25}$ GAYO I.111: Usu in manum conveniebat, quae anno continuo nupta perseverabat; quia enim velut annua possessione usucapiebatur, in familiam viri transibat filiaeque locum optinebat. Itaque lege duodecim tabularum cautum est, ut si qua nollet eo modo in manum mariti convenire, ea quotannis trinoctio abesset atque eo modo cuiusque anni usum interrumperet. Sed hoc totum ius partim legibus sublatum est, partim ipsa desuetudine obliteratum est.

${ }^{26}$ A propósito de la relación entre matrimonium y conventio in manum, vid. en VOLTERRA, La concepción du mariage á Rome, 2, 1955, pp.370ss. 
con régimen de separación de bienes y no integración en la familia del marido. Como se ha afirmado, de forma gráfica, en el viejo edificio de la familia agnaticia romana, la manus es el primer al que se desmorona. En la obra de Gayo, escrita a mediados del siglo II d.C., se afirma que la confarreatio, la coemptio y el usus, son formas matrimoniales que no comportan ya la adquisición de la potestad marital sobre la esposa ${ }^{27}$.

d) La disolución de un matrimonio cum manu, produce la extinción de la potestad marital sobre la mujer, la segregación de ésta de la familia de su marido, y la reincorporación de ésta a su familia originaria o bien la reintegración a su anterior posición jurídica, si era sui iuris.

El matrimonio clásico, ha escrito Voci, ojo suprimir :de forma brillante se inspira en principios nuevos, profundamente diversos de los propios del matrimonio arcaico. En crisis la religión familiar, la idea de la perpetuidad de la familia, y el propio significado religioso del matrimonio, el divorcio deja de estar sometido a un régimen de justas causas, y desaparecida la manus, marido y mujer aproximan su posición jurídica en el seno de la comunidad conyugal. NOTA, VOCI, Istituzioni di Diritto Romano, Milanoi954,pp.467 ss. AÑADIR EN TEXTO: .Por el contrario, VOLTERRA ha resaltado en sus numerosos estudios atinentes al matrimonio, la sustancial continuidad y la unidad de naturaleza del matrimonio romano a lo largo de las distintas etapas históricas como consortium omnis vitae, conforme a la definición de Modestino.

\section{Uniones de hecho. Contubernium.}

Diferente del matrimonio libre matrimonio o matrimonio sine manu, es la unión libre o unión de hecho, a la que se da la denominación en Derecho romano de concubinatus, entre dos personas libres, que deciden convivir, sin intención matrimonial. Así Paulo afirma que debe estimarse que es concubina la que un hombre tiene en tal condición por la mera intención. Dicha unión de hecho entre dos personas, que recibió una regulación diferente en las distintas etapas históricas, producía determinados efectos jurídicos, pero no los propios de unas justas nupcias, iustae nuptiae, como eran, la condición de legítimos de los hijos nacidos de la relación, la atribución de la patria potestad respecto de la mujer y de los hijos comunes, la consideración de dotales de los bienes aportados por la mujer etc....

Observa FUENTESECA, que sólo en el matrimonium legitimum, también denominado iustae nuptiae, los hijos seguían la condición legal del pater y continuaban su estirpe familiar (nomen familiae). En definitiva, sólo el matrimonio

${ }^{27}$ GAYO I.1.111 y 114 . 
legítimo produciría nuevos ciudadanos, y era, en este sentido, una fuente de ciudadanía. El matrimonio parecía interesar a los juristas únicamente desde el punto de vista del control de la nueva ciudadanía. En el fondo ésta sería la razón del ius conubii que era un control sobre la ciudadanía y, por tanto, un principio político de la civitas $^{28}$.

En las fuentes jurídicas y literarias, y en especial en las inscripciones funerarias, hay textos en los que se pone de manifiesto la estabilidad ${ }^{29}$, afectividad y publicidad de muchas de estas uniones, respecto de las que la imposibilidad legal de contraer matrimonio o la ausencia de interés por asumir el compromiso o el proyecto de matrimonio, producía como consecuencia, aparte de los efectos jurídicos ya señalados, la ausencia del honor matrimonii y del otorgamiento a la mujer del rango social de su marido.

Las personas que iniciaban su vida en común, sin intención de constituir un matrimonio, dado que faltaba la affectio maritalis, pertenecían en muchos de los supuestos a diferentes estratos sociales, lo que en sí mismo condicionaba, en ocasiones, la decisión de no formalizar un matrimonio legítimo, matrimonium iustum. La propia ley presumía que la relación estable de convivencia entre personas de análoga condición social constituía un matrimonio, salvo que las personas fuesen de diferente condición social, en cuyo caso la ley presumía, siempre claro está salvo prueba o manifestación en contrario, que se estaba en presencia de una unión libre o de hecho, es decir, de un concubinato. Bastaba, en todo caso, un cambio de intención para que la unión de hecho pasase a ser un matrimonio o a la inversa, siempre que no existiese al respecto un impedimento legal.

La tolerancia social y legal, llega incluso hasta el punto de propiciar la relación de hecho entre patrono y su liberta, así se manifiesta Ulpiano, en su comentario a la Lex Iulia et Papia Poppaea nuptialis, del 9 d.C. al afirmar que es más honorable para un patrono tener a su liberta como concubina que como mujer legítima $^{30}$. La Ley de Augusto, si bien trataba de favorecer el matrimonio, en la

${ }^{28}$ FUENTESECA, Derecho privado romano, Madrid 1978, pp.387-88.

${ }^{29}$ La estabilidad diferencia al concubinato de la mera relación sexual. Vid., CASTELLI, Il concubinato e la legislazione augustea, en BIDR 27 (1914) 55 ss.; CASTELLO, In tema di matrimonio e concubinato nel mondo antio, Milano 1940; VOLTERRA, s.v. Concubinato, en NNDI 3 (1959), 1952;. Ghirardi, Regulación jurídica de las conductas sexuales extramatrimoniales en derecho romano, Revista General de Derecho Romano IUSTEL, n.5, diciembre 2005

${ }^{30}$ D.25.7.1: Ulpianus 2 ad 1. iul. et pap. "Quae in concubinatu est, ab invito patrono poterit discedere et alteri se aut in matrimonium aut in concubinatum dare? ego quidem probo in concubina adimendum ei conubium, si patronum invitum deserat, quippe cum honestius sit patrono libertam concubinam quam matrem familias habere".

D.25.7.1.1: Ulpianus 2 ad 1. iul. et pap. "Cum atilicino sentio et puto solas eas in concubinatu habere posse sine metu criminis, in quas stuprum non committitur”. 
práctica supuso un incremento de las uniones de hecho, al prohibir el matrimonio a los soldados, así como entre senadores y libertas y entre ingenuos y personas consideradas de mala reputación.

En unos casos, la unión de hecho respondía a la prohibición de que la pareja pudiese contraer matrimonio, lo que por ejemplo se produciría en el caso de una relación estable entre personas del mismo sexo, que en todo caso no constituía un concubinato en sentido técnico, o en los supuestos de coexistencia de una relación matrimonial con una relación de hecho, lo que, por otra parte, no era, en principio, objeto de prohibición legal, si bien con Augusto se castigan penalmente las relaciones extramatrimoniales tipificadas como adulterium, incestum o stuprum $^{31}$. En otros supuestos la unión de hecho respondía a la libre voluntad de quienes no deseaban, por la razón que fuese, contraer matrimonio. Marciano, citando a Marcelo afirma, al respecto, en un texto contenido en el Digesto ${ }^{32}$, que el concubinato no está penado por la ley, ya que son las mismas leyes las que dieron nombre al concubinato.

La cuestión de la denominación de las uniones libres o de hecho preocupa también a los juristas y a la sociedad de su tiempo ${ }^{33}$. Al cambio de vocablo para aludir a la mujer y evitar una posible connotación negativa se refiere Paulo cuando afirma que: para designar a la mujer que vive con el hombre sin ser su esposa legítima, los antiguos utilizaban la denominación de manceba y que en su tiempo con mayor discreción se le suele llamar amiga ${ }^{34}$.

El emperador Constantino aproxima la regulación del concubinato a la del matrimonio en cuanto a los requisitos exigibles, así en materia de monogamia, pubertad e impedimentos de parentela y afinidad ${ }^{35}$, al tiempo que deroga algunas

${ }^{31}$ D. 25.7.3.pr. Ulpianus 2 ad 1. iul. et pap. "Si qua in patroni fuit concubinatu, deinde filii esse coepit vel in nepotis, vel contra, non puto eam recte facere, quia prope nefaria est huiusmodi coniunctio, et ideo huiusmodi facinus prohibendum est"; D.48.5.35.pr: Modestinus 1 reg. "Stuprum committit, qui liberam mulierem consuetudinis causa, non matrimonii continet, excepta videlicet concubina".

32 D.25.7.3.1: Marcianus 12 inst. "Nec adulterium per concubinatum ab ipso committitur. nam quia concubinatus per leges nomen assumpsit, extra legis poenam est, ut et Marcellus libro septimo digestorum scripsit".

${ }^{33}$ Acerca de la significación del término paelex, para referirse a la mujer que convive con un hombre en una unión de hecho, vid. En FERNÁNDEZ VAQUERO, Aspectos sobre el matrimonio en el Derecho romano arcaico, en El Derecho de familia: de Roma al Derecho actual, Huelva 2004, pp.205 y ss. Y la bibliografía allí citada.

${ }^{34}$ D.50.16.144: Paulus 10 ad 1. iul. et pap. "Libro memorialium massurius scribit " pellicem" apud antiquos eam habitam, quae, cum uxor non esset, cum aliquo tamen vivebat: quam nunc vero nomine amicam, paulo honestiore concubinam appellari. granius flaccus in libro de iure papiriano scribit pellicem nunc volgo vocari, quae cum eo, cui uxor sit, corpus misceat: quosdam eam, quae uxoris loco sine nuptiis in domo sit, quam pallakyn graeci vocant".

${ }^{35}$ D.25.7.1.3 y 4: Ulpianus 2 ad 1. iul. et pap. "Si qua in patroni fuit concubinatu, deinde filii esse coepit vel in nepotis, vel contra, non puto eam recte facere, quia prope nefaria est huiusmodi coniunctio, et ideo huiusmodi facinus prohibendum est". D.25.7.1.4: Ulpianus 2 ad 1. iul. et pap. "Cuiuscumque aetatis concubinam habere posse palam est, nisi minor annis duodecim sit"; 
de las disposiciones penales de Augusto referidas a las uniones de hecho. En la práctica, la unión de hecho se diferencia del matrimonio sólo en atención a la ausencia de affectio maritalis ${ }^{36}$. En general, la legislación cristiana tiende a reforzar el matrimonio, a dificultar la existencia de las uniones de hecho y a facilitar su transición a relaciones matrimoniales. Al propio tiempo, se mejoró la condición de los hijos nacidos de estas uniones, que son denominados naturales y a los que se concede el derecho de alimentos y derechos sucesorios abintestato, así como se reconoce la posibilidad de que sean legitimados por subsiguiente matrimonio de los padres, rescripto imperial u oblación a la curia.

Alas personas esclavas no se les reconocía capacidad para contraer matrimonio, conubium, por lo que las uniones entre esclavos o entre una persona libre y una persona esclava no eran válidas y recibían la denominación de contubernium. ${ }^{37}$

\section{Esponsales}

Frente a la complejidad y a la duración prolongada en el tiempo que caracteriza, en general, la formalización del compromiso matrimonial en las legislaciones y tradiciones de los pueblos primitivos, la casi total ausencia de formalidades y el nacimiento del vínculo matrimonial en un sólo momento, constituye un elemento diferenciador esencial del matrimonio romano, asumido por el Derecho canónico y por los ordenamientos jurídicos modernos.

En época arcaica, la constitución del vínculo matrimonial, exigiría una previa promesa de futuro matrimonio, que se formalizaría a través un contrato verbal de sponsio, de ahí el término sponsalia, mediante el cual la propia mujer si era sui iuris, con la auctoritas de su tutor, o el paterfamilias a cuya potestas estuviese sometida, si era alieni iuris, se comprometía con el futuro esposo o con su paterfamilias a contraer futuro matrimonio ${ }^{38}$. Con carácter alternativo, se acordaría que el caso de que la mujer no contrajese matrimonio debería entregar a su prometido una cantidad de dinero a título de pena, lo que sería exigible a través de la actio ex sponsu. ${ }^{39}$

En época clásica, desaparece el formalismo en los esponsales ${ }^{40}$, así como la sanción indemnizatoria en caso de incumplimiento, que es considerada nula en

${ }^{36}$ D.25.7.4: Paulus 19 resp. Concubinam ex sola animi destinatione aestimari oportet.

${ }^{37}$ Tituli ex corpore Ulpiani, 5.5: Cum servis nullum est conubium y Pauli Sententiarum, 2.19.6 : Inter servos et liberos matrimonium contrahi non potest, contubernium potest.

${ }^{38}$ Vid sobre el formalismo y el carácter arcaico de los esponsales en Aulo Gelio, Noctes Atticae, IV.4 y VARrón, De Lingua Latina, VI, 69-72.

${ }^{39}$ Sobre el papel del ius sacrum en los esponsales, vid. Astolfi, Il fidanzamento nel diritto romano, Milano 1994, pp.4 ss.

${ }^{40}$ D.23.1.4: Ulpianus 35 ad sab. Sufficit nudus consensus ad constituenda sponsalia. 
caso de que se hubiere previsto. En este sentido se pronuncia Paulo cuando afirma que «Sería contrario a la honestidad, obligar al matrimonio bajo la amenaza de una pena $\rangle^{41}$. Se establece asimismo de forma expresa la necesidad de consentimiento de quienes contraen los esponsales ${ }^{42}$, si bien en el caso de la hija de familia bastaría su no oposición ${ }^{43}$. Probablemente en Derecho Justinianeo, la hija de familia la oposición de la hija de familia debería basarse en motivos justificados ${ }^{44}$.

Los esponsales en la época clásica constituirían en esencia un vínculo moral entre los futuros esposos, al que se añadirían determinados efectos jurídicos, en orden por ejemplo a la exención de declarar como testigos el uno contra el otro de los prometidos o el reconocimiento de acciones a favor del desposado por ofensas contra su prometida.

En el Derecho postclásico, por influencia de la moral cristiana aumentan los efectos jurídicos de los esponsales, estableciéndose por ejemplo una cuasiafinidad de los prometidos a efectos de impedimentos matrimoniales o la equiparación al adulterio de la infidelidad de la prometida, lo que aproxima la institución al matrimonio, al propio tiempo que se vuelven a admitir sanciones patrimoniales como consecuencia del incumplimiento de la promesa de futuras nupcias, lo que se materializa en lo previsto al efecto en materia de donaciones esponsalicias y de $\operatorname{arras}^{45}$.

\section{F. Naturaleza JURÍDica}

La naturaleza jurídica del matrimonio romano ha sido objeto de intenso debate doctrinal. Parece, en todo caso, que se ha producido una evolución desde su originaria configuración en la etapa arcaica hasta su conformación en el derecho

${ }^{41}$ D.45.1.134.pr.: Paulus 15 resp. Titia, quae ex alio filium habebat, in matrimonium coit gaio seio habente familiam: et tempore matrimonii consenserunt, ut filia gaii seii filio titiae desponderetur, et interpositum est instrumentum et adiecta poena, si quis eorum nuptiis impedimento fuisset: postea gaius seius constante matrimonio diem suum obiit et filia eius noluit nubere: quaero, an gaii seii heredes teneantur ex stipulatione. respondit ex stipulatione, quae proponeretur, cum non secundum bonos mores interposita sit, agenti exceptionem doli mali obstaturam, quia inhonestum visum est vinculo poenae matrimonia obstringi sive futura sive iam contracta.

${ }^{42}$ D.23.1.13: Paulus 5 ad ed. Filio familias dissentiente sponsalia nomine eius fieri non possunt. y D.23.1.11: Iulianus 16 dig. Sponsalia sicut nuptiae consensu contrahentium fiunt: et ideo sicut nuptiis, ita sponsalibus filiam familias consentire oportet:

${ }^{43}$ D.23.1.6.: Ulpianus 36 ad sab. Si puellae tutores ad finienda sponsalia nuntium miserunt, non putarem suffecturum ad dissolvendam nuptiarum spem hunc nuntium, non magis quam sponsalia posse eos solos constituere, nisi forte omnia ista ex voluntate puellae facta sint.

${ }^{44}$ D.23.1.12.1: Ulpianus 1.S. de sponsal. Tunc autem solum dissentiendi a patre licentia filiae conceditur, si indignum moribus vel turpem sponsum ei pater eligat.

${ }^{45}$ Vid.VOLTERRA, Ricerche intorno agli sponsali in diritto romano, BIDR, 40, 1932, pp. $87 \mathrm{ss}$; Id. Ancora sul consenso della filia familia agli sponsali, RISG, 10, 1935, pp.3 y ss Id. Studi sullárrha sponsalicia,RISG,2,1927, pp.671ss..; BALESTRI, s.v. sponsali (diritto romano), ED., XLIII, 1990 pp.500ss, y Fernández Baquero, Conubium y sponsalia, Estudios Homenaje a B. Reimundo, I, Burgos 2000, pp.197-216. 
justinianeo. Las principales tesis, no necesariamente contrapuestas en todos sus aspectos, avanzadas por los autores, se mueven en torno a las siguientes posiciones:

A) El matrimonio como mera situación que hecho, que se constituye por el inicio de la convivencia entre dos personas de distinto sexo ,y se mantiene por la simple intención de conservar la unión. No se requería, conforme a esta posición doctrinal, ninguna formalidad ni para constituir ni para mantener ni para disolver el vínculo conyugal .NOTA Vid al repecto en LONGO, Il requisito de la convivenza nella nozione romana di marimonio, AUMA,1955,pp.269ss.

B) El matrimonio como unión entre dos personas con base en un consensus inicial de constituir la relación, que deberá mantenerse ,como consensus continuado, mientras dura la intención de conservar el vínculo conyugal . Conforme a esta posión doctrinal la relación matrimonial se aproximaría a la contractual, en especial al contrato societario.NOTA Vid al respecto en ORESTANO, La struttura giuridica del matrimonio romano, dal diritto clásico al diritto giustinianeo, Milan 1951, y VOLTERRA, La conception du mariage d'aprés les juristes romains,Padova 1940,Id. Ancora sulla struttura del matrimonio clásico, Fest.. für Lübtow, Berlín 1980,pp.147-152.

C) El matrimonio clásico sería un tipo singular de contrato consensual ,con características propias de la relación personal que lo fundamenta .NOTA ViD. EN RASI, Consensus facit nuptias, Milan 1946.

D) En la época arcaica y republicana mas que de matrimonio habría que hablar de tipos o formas de matrimonio, conforme a las formalidades realizadas por los contrayentes al efecto de conformar la denominada conventio in manum.. NOTA Vid en BOZZA, Manus e matrimonio, Annales di Universitá de Macerata, XV,1942..

E) En el Derecho postclásico y justinianeo, se configura como elemento esencial el vínculo inicial que refleja la voluntad de los cónyuges, conforme al cual se constituye el matrimonio y que debe reforzarse y objetivarse mediante ritos y ceremonias laicas y religiosas, en detrimento de la voluntad de mantener le relación conyugal, que pasa a un segundo término, al propio tiempo que se restringen y aumentan las dificultades para disolver el vínculo matrimonial . NOTA Vid. en ALBERTARIO, Il consenso dgli sposi e la perpetuita del matrimonio nel diritto romano e nei Padri della Chiesa, SDHI,5, 1939, pp. 18-75. y ROBLEDA, El matrimonio en Derecho ,Roma 1970. 


\section{REFLEXÕES SOBRE A REALIDADE SOCIAL, A TRADIÇÃO JURÍDICA E A MORAL CRISTÃ NO MATRIMÔNIO ROMANO}

Resumo: O matrimônio, como toda instituição que tem uma tradição secular, é um produto histórico. Constitui a expressão em cada época de uma moral e de usos sociais, na qual se refletem, em intensidades distintas, as tensões, equilíbrios, resistências e oscilações, que as novas realidades ou mudanças de mentalidade numa parte do universo social produzem na valoração intrínseca da instituição, assim como no jogo de forças contrárias que pretendem a sua manutenção ou reforma. Somente a partir da interpretação das fontes de conhecimento que moldam a experiência histórica que pressupõe a clássica, e sempre latente, tensão entre uma concepção leiga e secular do matrimônio e outra própria de uma moral sagrada e canônica, poder-se-á proceder com fundamento a uma adequada valoração da realidade presente, de sua regulamentação jurídica e, no caso, a uma eventual reforma. O modelo matrimonial, que caracteriza, em boa medida, nas suas diferentes perspectivas, a denominada tradição de pensamento ocidental europeu e americano, tem suas principais fontes no Direito Romano e no Direito Canônico. Porém, diante desta afirmação, que parece ser de caráter induvidoso, os autores não concordam sobre o papel e o grau de influência exercido por cada uma destas fontes. Chegaram inclusive a afirmar que a instituição do matrimônio romano constitui a maior das criações do seu gênio jurídico, perante outros estudiosos que, em pólo oposto, entendem que o matrimônio é a instituição onde mais falhou o gênio jurídico de Roma.

Palabras clabe: Matrimónio. Derecho Romano. Naturaleza jurídica. 